\title{
Telas de Sombreamento e Substratos na Produção de Mudas de Dipteryx alata Vog.
}

\author{
Edilson Costa ${ }^{1}$, Jessica Garcia Dias ${ }^{1}$, Karina Garcia Lopes ${ }^{1}$, \\ Flávio Ferreira da Silva Binotti ${ }^{1}$, Eliana Duarte Cardoso ${ }^{1}$
}

${ }^{1}$ Unidade Universitária de Cassilândia, Universidade Estadual de Mato Grosso do Sul - UEMS, Cassilândia/MS, Brasil

\begin{abstract}
RESUMO
Este trabalho avaliou tecnologias de ambientes protegidos e substratos para a produção de mudas de Dipteryx alata Vog. Foram utilizados dois ambientes protegidos: telado agrícola, fechamento em $90^{\circ}$ graus, com tela preta nas laterais e aluminizada na cobertura, ambas de $50 \%$ de sombreamento; telado agrícola, fechamento em $45^{\circ}$ graus, com tela preta nas laterais e cobertura, de $50 \%$ de sombreamento. Em cada ambiente foram testados substratos de mistura de esterco bovino (E) e vermiculita (V): $100 \% \mathrm{E}+0 \% \mathrm{~V} ; 90 \% \mathrm{E}+10 \% \mathrm{~V} ; 80 \% \mathrm{E}+20 \% \mathrm{~V} ; 70 \% \mathrm{E}+30 \% \mathrm{~V} ; 60 \% \mathrm{E}+40 \%$ $\mathrm{V} ; 50 \% \mathrm{E}+50 \% \mathrm{~V} ; 40 \% \mathrm{E}+60 \% \mathrm{~V} ; 30 \% \mathrm{E}+70 \% \mathrm{~V} ; 20 \% \mathrm{E}+80 \% \mathrm{~V} ; 10 \% \mathrm{E}+90 \% \mathrm{~V}$. O telado preto propiciou mudas de melhor qualidade e os substratos com baixas porcentagens de esterco (10, 20 e 30\%) são os mais propícios para a formação de mudas de Dipteryx alata Vog.
\end{abstract}

Palavras-chave: baru, esterco bovino, vermiculita, ambientes protegidos.

\section{Shading Screens and Substrates for Dipteryx alata Vog. Seedling Production}

\begin{abstract}
This study evaluated the technologies of protected environments and substrates for the production of Dipteryx alata Vog. seedlings. Two protected environments were used: agricultural screened, closing at 90 degrees, with black screen on the sides and aluminized screen on the cover, both with 50\% shading; agricultural screened, closing at 45 degrees, with black screen on the sides and cover, both with $50 \%$ shading. In each environment, substrates composed of mixture of cattle manure (E) and vermiculite $(\mathrm{V})$ at the following ratios were tested: $100 \% \mathrm{E}+0 \% \mathrm{~V} ; 90 \% \mathrm{E}+10 \%$ $\mathrm{V} ; 80 \% \mathrm{E}+20 \% \mathrm{~V} ; 70 \% \mathrm{E}+30 \% \mathrm{~V} ; 60 \% \mathrm{E}+40 \% \mathrm{~V} ; 50 \% \mathrm{E}+50 \% \mathrm{~V} ; 40 \% \mathrm{E}+60 \% \mathrm{~V} ; 30 \% \mathrm{E}+70 \%$; $20 \% \mathrm{E}+80 \% \mathrm{~V} ; 10 \% \mathrm{E}+90 \% \mathrm{~V}$. The black screen environment propitiates seedlings of better quality and the substrates with low percentages of cattle manure $(10,20$ and $30 \%)$ are the most propitious for the formation of Dipteryx alata Vog. seedlings.
\end{abstract}

Keywords: baru, cattle manure, vermiculite, protected environments. 


\section{INTRODUÇÃO E OBJETIVOS}

O baruzeiro (Dipteryx alata Vog.), espécie arbórea de distribuição irregular na paisagem do Cerrado, apresenta diversos usos, tanto a planta como os frutos (Vera \& Souza, 2009). As plantas são utilizadas para sombreamento em pastagens, recuperação de áreas degradadas e sua madeira é utilizada na construção civil. Dos frutos são consumidos a polpa (farinha e doces) e as sementes torradas (amêndoas) (Silva et al., 1994; Sano et al., 2004; Vera \& Souza, 2009), além da extração de óleo (Sano et al., 2004; Vera \& Souza, 2009).

Pela rusticidade e capacidade de adaptação, o baruzeiro apresenta grande potencial em sistemas produtivos (Sano et al., 2004; Vera \& Souza, 2009), contudo a espécie manifesta estagnação no crescimento de mudas no período de inverno (julho a setembro) e atingem $21,0 \mathrm{~cm}$ de altura em 12 meses, com diâmetro médio de $6,9 \mathrm{~mm}$ (Ferreira et al., 1998). Segundo Corrêa et al. (2000), períodos de pós-maturação de sementes de Dipteryx alata Vog., por dois meses, propiciam elevados porcentuais de emergência de plântulas com plantel uniforme e existe alta variabilidade dessa espécie em função da sua região de origem. Para a formação das mudas, Fonseca et al. (1994) destacam que a semeadura deve ser realizada entre 1 e $3 \mathrm{~cm}$ de profundidade.

A etapa de produção de mudas é fase fundamental para obtenção da uniformidade das plantas. Nessa fase, o tipo de substrato, tipo de ambiente protegido, o volume de recipiente, a irrigação, a adubação e o manejo correto das operações de produção propiciam condições para obtenção de plantas com elevada qualidade, para garantir o sucesso no desenvolvimento a campo. Segundo Mota et al. (2012), para o plantio ou replantio de espécies em florestas naturais ou em reflorestamento, assim como na produção de mudas de elevada qualidade, o conhecimento da ecofisiologia da germinação/emergência e crescimento inicial das espécies são requisitos fundamentais para o sucesso da atividade.

Dentre os fatores importantes para obtenção de mudas de qualidade, o substrato se enquadra como elemento que promove influência sobre a formação inicial dos vegetais em recipientes (Peixoto, 1986; Costa et al., 2005), devendo-se dar especial atenção à sua escolha. Nesse contexto, cada espécie vegetal responde diferentemente ao tipo de substrato puro ou em misturas (Fachinello et al., 1995) e pesquisadores buscam identificar aqueles que promovem melhores condições e mudas de qualidade (Menezes \& Fernandes, 1999). Como é sabido, o sucesso da produção a campo se inicia com a formação de mudas de elevada qualidade. Carneiro (1976) destaca que em cultivo de Pinus taeda, aos 15 meses após o plantio, foi verificado que a idade da muda e o diâmetro do colo são fatores fundamentais na sobrevivência das mudas a campo, contudo a altura não foi fator de classificação de qualidade, sendo um parâmetro desnecessário de avaliação.

Aliado e interagindo com os substratos, o ambiente de cultivo protegido influência o desenvolvimento inicial da planta (Costa et al., 2009), agregando vigor às mudas e, consequentemente, melhor adaptação e pegamento a campo (Costa et al., 2011). Para Zanella et al. (2006), a utilização de sombreamento é uma importante técnica na formação de mudas frutíferas, pois afeta diretamente o crescimento da planta e posteriormente a formação do pomar.

Baseado nas informações relatadas e também na importância que a fruticultura assume no estado de Mato Grosso do Sul, especialmente na região de Cassilândia, verifica-se a necessidade de buscar conhecimentos sobre tecnologias de produção de mudas de alta qualidade e potencial genético, visando à sua sanidade e padrão produtivo.

Este trabalho teve o objetivo de estudar ambientes protegidos telados e substratos na emergência e formação inicial de mudas de Dipteryx alata Vog.

\section{MATERIAL E MÉTODOS}

Os experimentos com formação e crescimento inicial de mudas de Dipteryx alata Vog. em diferentes ambientes protegidos e substratos foram conduzidos na Universidade Estadual de Mato Grosso do Sul (UEMS), Unidade Universitária de Cassilândia - MS. O local possui latitude de $19^{\circ} 07^{\prime} 21^{\prime \prime} \mathrm{S}$, longitude de $51^{\circ} 43^{\prime} 15^{\prime \prime}$ W e altitude de $516 \mathrm{~m}$ (estação automática CASSILANDIA-A742). De acordo com a classificação climática de Köppen, apresenta Clima Tropical Chuvoso (Aw).

Foram utilizados dois ambientes protegidos: 1) Telado agrícola de estrutura em aço galvanizado possuindo $8,00 \mathrm{~m}$ de largura por $18,00 \mathrm{~m}$ de comprimento e 
4,00 m de altura; fechamento em $90^{\circ}$ graus, com tela preta nas laterais e aluminizada na cobertura, ambas de $50 \%$ de sombreamento (A1); 2) Telado agrícola de estrutura em aço galvanizado possuindo $8,00 \mathrm{~m}$ de largura por 18,00 $\mathrm{m}$ de comprimento e 3,50 m de altura, fechamento em $45^{\circ}$ graus, com tela preta nas laterais e cobertura, de $50 \%$ de sombreamento (A2). As inclinações de $45^{\circ}$ (A2) e $90^{\circ}$ (A1) das telas laterais são apenas detalhes construtivos dos ambientes protegidos utilizados pelas empresas especializadas e não constituem objeto de estudo do presente trabalho.

No interior dos ambientes protegidos, as mudas de Dipteryx alata Vog. foram formadas por sementes, em sacolas de polietileno $(15,0 \times 25,0 \mathrm{~cm})$, com capacidade de 1,8 litro, preenchidas com substratos oriundos das combinações de misturas de esterco bovino (E) e vermiculita $(\mathrm{V})$ conforme Tabela 1 . Como a vermiculita é um mineral adquirido de empresas e atua como condicionante físico do substrato, foi realizada apenas a análise do esterco bovino (Tabela 2).

O esterco bovino foi compostado em local coberto, com fornecimento de água de dois em dois dias e revolvimento. Esse procedimento foi realizado por um período de 30 dias, de 27/9/2012 até 27/10/2012. Para a mistura do esterco e da vermiculita, o esterco foi

Tabela 1. Substratos oriundos de mistura de esterco bovino e vermiculita, em Cassilândia, MS, novembro de 2012 a janeiro de 2013.

Table 1. Substrates from mixed of cattle manure and vermiculite. Cassilândia-MS, November-2012 to January-2013.

\section{Esterco bovino $(\mathrm{E})+$}

\section{Vermiculita (V)}

$\mathrm{S} 1=100 \%$ de $\mathrm{E}+0 \%$ de $\mathrm{V}$; $\mathrm{S} 2=90 \%$ de $\mathrm{E}+10 \%$ de $\mathrm{V}$; $\mathrm{S} 3=80 \%$ de $\mathrm{E}+20 \%$ de $\mathrm{V}$; $\mathrm{S} 4=70 \%$ de $\mathrm{E}+30 \%$ de $\mathrm{V}$; $\mathrm{S} 5=60 \%$ de $\mathrm{E}+40 \%$ de $\mathrm{V}$;
$\mathrm{S} 6=50 \%$ de $\mathrm{E}+50 \%$ de $\mathrm{V}$ $\mathrm{S} 7=40 \%$ de $\mathrm{E}+60 \%$ de $\mathrm{V}$; $\mathrm{S} 8=30 \%$ de $\mathrm{E}+70 \%$ de $\mathrm{V}$; S9 $=20 \%$ de $\mathrm{E}+80 \%$ de $\mathrm{V}$; $\mathrm{S} 10=10 \%$ de $\mathrm{E}+90 \%$ de $\mathrm{V}$. peneirado em peneira com diâmetro de $70 \mathrm{~cm}$ e malha $3,70 \mathrm{~mm}$, para melhor homogeneização. Foi utilizada vermiculita com textura superfina. As características químicas do esterco estão na Tabela 2.

As sementes foram extraídas em morsa mecânica e manual. A profundidade de semeadura foi de 1 a $3 \mathrm{~cm}$. Foram semeadas no dia 17 de novembro de 2012 duas sementes por recipiente; posteriormente foi realizado o desbaste, deixando-se uma planta. A emergência ocorreu aos 10 dias após a semeadura (DAS) e a estabilização, aos 19 DAS. O procedimento para caracterizar a estabilização foi o seguinte: foram realizadas contagens diárias de plantas emergidas em função da quantidade de sementes. Depois da repetição do resultado da contagem em três dias consecutivos no substrato $\mathrm{S} 3=80 \%$ de $\mathrm{E}+20 \%$ de $\mathrm{V}$, no interior do ambiente de tela aluminizada, cessaram as anotações.

Inicialmente foram mensurados o índice de velocidade de emergência (IVE) proposto por Maguire (1962), a porcentagem de emergência (PE) na estabilização do tratamento mais veloz e o tempo médio de emergência (TME) proposto por Labouriau (1983). A irrigação foi realizada de forma manual, procurando não encharcar os substratos e mantê-los em boas condições para o desenvolvimento radicular.

Foram mensuradas a altura da planta, com régua milimetrada (AP), o número de folhas (NF), o número de folíolos (NFo) aos 30 e 65 dias após a semeadura (DAS). Aos 65 DAS também foram mensurados o diâmetro do colo (DC), a biomassa seca da parte aérea (MSA) e a biomassa seca do sistema radicular (MSR). Foram determinadas a biomassa seca total (MST), relação da altura e biomassa seca da parte aérea (RAM), relação da altura da parte aérea e diâmetro do colo (RAD), também explicitada pela sigla $H / D$ na avaliação de mudas de espécies florestais (Chaves et al., 2006;

Tabela 2. Análise química do esterco bovino utilizado no experimento, em Cassilândia, MS, novembro de 2012 a janeiro de 2013.

Table 2. Chemical analysis of cattle manure used in experiment. Cassilândia-MS, November-2012 to January-2013.

\begin{tabular}{cccccccc}
\hline $\mathrm{N}$ & \multicolumn{9}{c}{$\mathbf{g ~ k g}^{-\mathbf{1}}$} & $\mathrm{Ca}$ & $\mathrm{Mg}$ & $\mathrm{S}$ & $\mathrm{C}$ & $\mathrm{MO}$ \\
18,4 & $\mathrm{P}$ & $\mathrm{K}$ & 15,05 & 0,7 & 1,95 & 141 & 244 \\
- & 1,71 & 1 & & $\mathrm{mg} \mathrm{kg}^{-1}$ & & & \\
$\mathrm{pH}$ & - & - & $\mathrm{Cu}$ & $\mathrm{Zn}$ & $\mathrm{Fe}$ & $\mathrm{Mn}$ & $\mathrm{B}$ \\
5,4 & 38,91 & 0 & 18,5 & 125 & 6830 & 214 & 14 \\
\hline
\end{tabular}

$\mathrm{U}=$ Umidade; $\mathrm{MO}$ = Matéria orgânica; $\mathrm{C} / \mathrm{N}$ = Relação carbono/nitrogênio; $\mathrm{pH}$ em água. 
Carneiro et al., 2007), na qual $\mathrm{H}$ corresponde à altura da parte aérea e $\mathrm{D}$, ao diâmetro do colo, relação biomassa seca aérea e radicular (RMS) e índice de qualidade de Dickson (Dickson et al., 1960).

Por não haver repetições dos ambientes de cultivo, cada um foi considerado um experimento. Para cada ambiente de cultivo foi adotado o delineamento experimental inteiramente casualizado para avaliação dos substratos, com cinco repetições de seis mudas cada. Os ambientes foram avaliados pela análise de grupos de experimentos (Banzatto \& Kronka, 2006).

Os dados foram submetidos à análise de variância (teste $\mathrm{F}$ ) e as médias comparadas pelo teste de Scott-Knott a $5 \%$ de probabilidade para os substratos e pelo próprio teste F para os ambientes de cultivo, com o software Sisvar (Ferreira, 2010).

\section{RESULTADOS E DISCUSSÃO}

No telado preto não houve diferença no índice de velocidade de emergência de plântulas de Dipteryx alata Vog. nos diferentes substratos testados, assim como na porcentagem de emergência nesse ambiente e no ambiente com tela aluminizada (Tabela 3). No ambiente com tela aluminizada, os substratos com $50 \%, 40 \%$ e $20 \%$ de esterco propiciaram menores índices de velocidade de emergência (Tabela 3), diferentemente do observado por Costa et al. (2012), que constataram menores índices em substratos com maiores porcentagens de esterco e verificaram maiores índices no substrato com $100 \%$ de vermiculita. Mota et al. (2012) verificaram que os níveis de sombreamento $0 \%, 50 \%$ e $70 \%$ não influenciaram na emergência das plântulas, entretanto o melhor crescimento foi observado no telado de $50 \%$ de sombreamento, similar ao observado no presente trabalho.

Nas plântulas do tratamento $\$ 8$, no ambiente com tela aluminizada, foi observado maior índice de velocidade de emergência e maior porcentagem de emergência que nas plântulas do telado preto (Tabela 3), resultado esse que está de acordo com os obtidos por Costa et al. (2012). No presente trabalho, a maior porcentagem de emergência verificada quando houve a estabilização do tratamento mais veloz foi de $83,33 \%$, superior à observada por Costa et al. (2012), que foi de $66,1 \%$. O máximo IVE foi de 4,78 plantas por dia, enquanto Costa et al. (2012), na região de Aquidauana, MS, encontraram 1,39 plantas por dia num experimento realizado de 28 de setembro a 12 de dezembro de 2010. Mota et al. (2012) avaliaram níveis de sombreamento de $0 \%$ (pleno sol), $50 \%$ e $70 \%$ no crescimento de mudas de Dipteryx alata Vog. e verificaram, no nível de $50 \%$ de sombreamento, $75 \%$ de emergência e 1,28 plantas por dia de IVE, resultados inferiores ao do presente estudo.

Tabela 3. Efeito do ambiente e da composição do substrato no índice de velocidade de emergência, na porcentagem de emergência e no tempo médio de emergência de Dickson de Dipteryx alata Vog., em Cassilândia, MS, novembro de 2012 a janeiro de 2013.

Table 3. Effects of environment and substrate composition on emergence speed index, on emergence percentage and on emergence average time of Dipteryx alata Vog. Cassilândia-MS, November-2012 to January-2013.

\begin{tabular}{|ccccccc} 
& \multicolumn{2}{c}{ Índice de velocidade de emergência } & \multicolumn{2}{c}{ Porcentagem de emergência } & \multicolumn{2}{c}{ Tempo médio de emergência } \\
\cline { 2 - 7 } & Tela preta & Tela aluminizada & Tela preta & Tela aluminizada & Tela preta & Tela aluminizada \\
\hline S1 & $4,42 \mathrm{Aa}$ & $4,11 \mathrm{Aa}$ & $71,67 \mathrm{Aa}$ & $70,00 \mathrm{Aa}$ & $15,45 \mathrm{Aa}$ & $15,47 \mathrm{Ba}$ \\
\hline $\mathrm{S} 2$ & $3,90 \mathrm{Aa}$ & $3,87 \mathrm{Aa}$ & $66,67 \mathrm{Aa}$ & $76,67 \mathrm{Aa}$ & $15,80 \mathrm{Aa}$ & $15,71 \mathrm{Ba}$ \\
\hline $\mathrm{S} 3$ & $3,81 \mathrm{Aa}$ & $4,24 \mathrm{Aa}$ & $68,33 \mathrm{Aa}$ & $83,33 \mathrm{Aa}$ & $15,63 \mathrm{Aa}$ & $15,84 \mathrm{Aa}$ \\
\hline S4 & $4,58 \mathrm{Aa}$ & $4,16 \mathrm{Aa}$ & $81,67 \mathrm{Aa}$ & $75,00 \mathrm{Aa}$ & $15,63 \mathrm{Aa}$ & $15,68 \mathrm{Ba}$ \\
\hline S5 & $3,99 \mathrm{Aa}$ & $4,46 \mathrm{Aa}$ & $78,33 \mathrm{Aa}$ & $68,33 \mathrm{Aa}$ & $15,92 \mathrm{Aa}$ & $15,42 \mathrm{Bb}$ \\
\hline S6 & $4,26 \mathrm{Aa}$ & $3,33 \mathrm{Ba}$ & $70,00 \mathrm{Aa}$ & $68,33 \mathrm{Aa}$ & $15,46 \mathrm{Ab}$ & $15,98 \mathrm{Aa}$ \\
\hline S7 & $3,77 \mathrm{Aa}$ & $3,13 \mathrm{Ba}$ & $63,33 \mathrm{Aa}$ & $70,00 \mathrm{Aa}$ & $15,63 \mathrm{Ab}$ & $16,16 \mathrm{Aa}$ \\
\hline S8 & $3,15 \mathrm{Ab}$ & $4,78 \mathrm{Aa}$ & $53,33 \mathrm{Ab}$ & $78,33 \mathrm{Aa}$ & $15,72 \mathrm{Aa}$ & $15,48 \mathrm{Ba}$ \\
\hline S9 & $3,71 \mathrm{Aa}$ & $3,09 \mathrm{Ba}$ & $65,00 \mathrm{Aa}$ & $68,33 \mathrm{Aa}$ & $15,64 \mathrm{Ab}$ & $16,06 \mathrm{Aa}$ \\
\hline S10 & $4,34 \mathrm{Aa}$ & $3,81 \mathrm{Aa}$ & $80,00 \mathrm{Aa}$ & $63,33 \mathrm{Aa}$ & $15,65 \mathrm{Aa}$ & $15,56 \mathrm{Ba}$ \\
\hline
\end{tabular}

Letras iguais, maiúsculas nas colunas e minúsculas nas linhas, para cada parâmetro, não diferem entre si pelo teste de Scott-Knott a $5 \%$ de probabilidade para os substratos e pelo teste $\mathrm{F}$ para os ambientes de cultivo; S1 = 100\% de E + 0\% de V; S2 = 90\% de E + 10\% de V; S3 = 80\% de E + 20\% de V; S4 = 70\% de E + 30\% de V; S5 = 60\% de E + 40\% de V; S6 = 50\% de E + 50\% de V; S7 = 40\% de E + $60 \%$ de V; S $8=30 \%$ de $\mathrm{E}+70 \%$ de V; S $9=20 \%$ de $\mathrm{E}+80 \%$ de V; S10 $=10 \%$ de $\mathrm{E}+90 \%$ de V. 
Para o tempo médio e velocidade média de emergência, no telado preto não houve diferenças nesses parâmetros. No telado aluminizado, os substratos $20 \%$, $40 \%, 50 \%$ e $80 \%$ de esterco propiciaram maior tempo médio de emergência. Para os substratos com 20\%, $40 \%, 50 \%$ e $80 \%$ de esterco, o telado preto propiciou melhores condições de emergência em comparação com o telado aluminizado, ou seja, num menor tempo (Tabela 3). O máximo tempo médio observado no presente trabalho foi de 16,16 dias, enquanto Costa et al. (2012) obtiveram 19,19 dias.

Para o índice de velocidade de emergência, assim como para a porcentagem de emergência, o sombreamento promovido pelos dois tipos de ambiente e suas telas assim como as inclinações delas não afetaram o crescimento inicial do Dipteryx alata Vog. Pezzopane et al. (2004) explicitam que a tela preta de $50 \%$ de sombreamento provoca uma atenuação média de $41 \%$ na radiação solar global. Para a tela aluminizada de 50\% de sombreamento, Rocha (2007) destaca que a atenuação na radiação global é de 54,4\% e Santos et at. (2010) relatam redução de 58,5\%. Observa-se que a tela aluminizada provoca maior atenuação da radiação global que a tela preta, contudo essas reduções de radiação interna nos ambientes não influenciaram a emergência do Dipteryx alata Vog., a qual se mostrou similar em ambos ambientes protegidos.

Não houve interação entre ambiente de cultivo e substratos para as variáveis: altura de plantas aos 30 dias após a semeadura, altura de plantas aos 65 dias após a semeadura, número de folhas, número de folíolos, biomassa seca da parte aérea, biomassa seca total, relação da altura e biomassa seca da parte aérea e relação da altura da parte aérea e diâmetro do colo (Tabela 4). Dessa forma foi avaliado o efeito isolado dos substratos.

A altura de planta não diferiu na avaliação aos 30 dias após a semeadura (DAS). Aos 65 DAS as maiores médias de altura de mudas foram observadas nos tratamentos contendo $30 \%$ a $70 \%$ de esterco em sua formulação. Carneiro (1976) relata que para mudas de Pinus taeda a medida de altura de planta não foi fator de classificação de qualidade, contudo o diâmetro do colo e a idade das mudas são fatores fundamentais na sobrevivência das mudas a campo. Para mudas de baruzeiro, no presente trabalho, a medida de altura isolada não destaca a qualidade na muda, mas em conjunto com outras variáveis como diâmetro e biomassa aérea pode indicar a sua qualidade, pois essa é uma variável utilizada na determinação do índice de qualidade de Dickson.

Para o número de folhas, os menores valores foram verificados nos substratos com menores quantidade de esterco (10\% e $20 \%$ ), assim como o número de folíolos (Tabela 4). O número de folha (6,03 folhas) aos 65 DAS obtido no substrato S2 foi superior ao observado por Ajalla et al. (2012) aos 60 DAE, que obtiveram 4,64 folhas. As plantas com maior número de folhas tendem a possuir uma maior área foliar, com maior tendência a conversão fotossintética e maior crescimento (Reis et al., 2013).

O diâmetro do colo não apresentou diferenças significativas entre os tratamentos, independentemente do ambiente de cultivo - a média geral obtida no telado preto foi de $4,64 \mathrm{~mm}$ e, no telado aluminizado, de 4,56 mm, aos 65 DAS. Costa et al. (2012), aos 75 DAS, verificaram diâmetro de 5,0 $\mathrm{mm}$ em plantas cultivadas em telado preto de $50 \%$ de sombreamento e de $4,9 \mathrm{~mm}$ em plantas cultivadas em telado aluminizado de $50 \%$ de sombreamento. Ajalla et al. (2012) obtiveram 5,4 mm aos 60 DAE e Mota et al. (2012), aos 125 DAS, obtiveram diâmetro de colo de 4,40 mm, ambos os dados obtidos em telado de $50 \%$ de sombreamento.

Os substratos S5, S6 e S8 propiciaram plantas com maior biomassa da parte aérea, assim como os substratos S6, S8 e S9, para a biomassa total (Tabela 4). Nota-se que, nos substratos oriundos de diversas mistura de esterco bovino e vermiculita, as proporções que possuíam menores quantidades de esterco (S8 e S9) foram favoráveis ao acúmulo de biomassa nas plantas, assim como obervado por Dias et al. (2009) em mudas de cafeeiro.

A relação altura e diâmetro do colo (RAD), também designada por H/D por Chaves et al. (2006) e Carneiro et al. (2007), determina o quão esbelta é a planta e é indicativa de estiolamento da muda na fase de viveiro e possível tombamento da planta a campo após o plantio (Carneiro, 1995). Essa razão demonstra o equilíbrio de crescimento (Carneiro, 1995) e determina a sobrevivência a campo, pois quanto menor seu valor, melhor a capacidade de sobrevivência da muda após o plantio (Carneiro, 1983).

$\mathrm{O}$ ambiente com tela preta propiciou plantas maiores $(18,90 \mathrm{~cm})$, com maiores massas totais $(3,316 \mathrm{~g} /$ planta $)$, 
Tabela 4. Efeito da composição de substratos: na altura de plantas aos 30 dias após a semeadura; na altura de plantas aos 65 dias após a semeadura; no número de folhas aos 65 dias após a semeadura; no número de folíolos aos 65 dias após a semeadura; na biomassa seca da parte aérea; na biomassa seca total; na relação da altura e biomassa seca da parte aérea; e na relação da altura da parte aérea e diâmetro do colo do Dipteryx alata Vog., em Cassilândia, MS, novembro de 2012 a janeiro de 2013.

Table 4. Effects of substrates composition on plant height at 30 day after sowing, on plant height at 65 day after sowing, on number of leaves, on number of leaflets, on aerial part dry biomass, on total dry biomass, on ratio of plant height and aerial part dry biomass, on ratio of plant height and stem diameter of Dipteryx alata Vog. Cassilândia-MS, November-2012 to January-2013.

\begin{tabular}{|ccccc|}
\hline & $\begin{array}{c}\text { Altura de planta } \\
\text { aos 30 dias }\end{array}$ & $\begin{array}{c}\text { Altura de planta } \\
\text { aos 65 dias }\end{array}$ & Número de folhas aos 65 dias & $\begin{array}{c}\text { Número de folíolos } \\
\text { aos 65 dias }\end{array}$ \\
\hline S1 & $7,29 \mathrm{~B}$ & $15,69 \mathrm{~B}$ & $5,72 \mathrm{~A}$ & $42,40 \mathrm{~A}$ \\
\hline S2 & $9,11 \mathrm{~A}$ & $17,23 \mathrm{~B}$ & $6,03 \mathrm{~A}$ & $42,41 \mathrm{~A}$ \\
\hline S3 & $9,32 \mathrm{~A}$ & $17,65 \mathrm{~B}$ & $5,66 \mathrm{~A}$ & $41,38 \mathrm{~A}$ \\
\hline S4 & $9,82 \mathrm{~A}$ & $19,39 \mathrm{~A}$ & $5,83 \mathrm{~A}$ & $42,06 \mathrm{~A}$ \\
\hline S5 & $9,92 \mathrm{~A}$ & $18,86 \mathrm{~A}$ & $5,88 \mathrm{~A}$ & $42,75 \mathrm{~A}$ \\
\hline S6 & $9,37 \mathrm{~A}$ & $18,50 \mathrm{~A}$ & $5,82 \mathrm{~A}$ & $42,03 \mathrm{~A}$ \\
\hline S7 & $9,70 \mathrm{~A}$ & $19,06 \mathrm{~A}$ & $5,78 \mathrm{~A}$ & $41,72 \mathrm{~A}$ \\
\hline S8 & $10,45 \mathrm{~A}$ & $20,15 \mathrm{~A}$ & $5,87 \mathrm{~A}$ & $43,42 \mathrm{~A}$ \\
\hline S9 & $10,01 \mathrm{~A}$ & $18,00 \mathrm{~B}$ & $5,38 \mathrm{~B}$ & $39,86 \mathrm{~B}$ \\
\hline S10 & $9,90 \mathrm{~A}$ & $17,11 \mathrm{~B}$ & $5,29 \mathrm{~B}$ & $37,16 \mathrm{C}$ \\
\hline & Biomassa seca da & Biomassa seca & Relação altura/biomassa & Relação altura e \\
\hline S1 & parte aérea & total da muda & seca da parte aérea & diâmetro \\
\hline S2 & $1,948 \mathrm{~B}$ & $2,473 \mathrm{D}$ & $8,18 \mathrm{~A}$ & $3,32 \mathrm{C}$ \\
\hline S3 & $2,190 \mathrm{~B}$ & $2,810 \mathrm{C}$ & $7,86 \mathrm{~A}$ & $3,70 \mathrm{~B}$ \\
\hline S4 & $2,316 \mathrm{~B}$ & $2,971 \mathrm{C}$ & $7,72 \mathrm{~A}$ & $3,73 \mathrm{~B}$ \\
\hline S5 & $2,434 \mathrm{~B}$ & $3,136 \mathrm{~B}$ & $8,11 \mathrm{~A}$ & $4,20 \mathrm{~A}$ \\
\hline S6 & $2,534 \mathrm{~A}$ & $3,194 \mathrm{~B}$ & $7,49 \mathrm{~A}$ & $4,00 \mathrm{~A}$ \\
\hline S7 & $2,692 \mathrm{~A}$ & $3,458 \mathrm{~A}$ & $6,96 \mathrm{~A}$ & $4,04 \mathrm{~A}$ \\
\hline S8 & $2,446 \mathrm{~B}$ & $3,237 \mathrm{~B}$ & $7,83 \mathrm{~A}$ & $4,24 \mathrm{~A}$ \\
\hline S9 & $2,877 \mathrm{~A}$ & $3,844 \mathrm{~A}$ & $7,20 \mathrm{~A}$ & $4,35 \mathrm{~A}$ \\
\hline
\end{tabular}

e maior relação entre a altura da parte aérea da planta e seu diâmetro do colo (Tabela 5) aos 65 dias após a semeadura (DAS). Aos 60 dias após a emergência (DAE), Ajalla et al. (2012) obtiveram plantas com altura de $19,8 \mathrm{~cm}$ em telado de tela preta de $50 \%$ de sombreamento, valor muito semelhante ao obtido no presente estudo aos 65 dias após a semeadura (DAS). Costa et al. (2012) recomendam ambos os ambientes telados (preto e aluminizado) para a formação de mudas de Dipteryx alata Vog., pois propiciaram mudas de elevada qualidade, porém aos 75 DAS as mudas apresentaram alturas menores $(13,6 \mathrm{~cm}$ e $14,1 \mathrm{~cm}$ no telado preto e aluminizado, respectivamente) e menores biomassas secas totais (1,98 e 2,19 g no telado preto e aluminizado, respectivamente) que as observadas no presente trabalho. Assim como os valores altura $(16,33 \mathrm{~cm})$ e biomassa total $(3,21 \mathrm{~g})$ obtidos aos 125 dias após a semeadura por Mota et al. (2012) foram menores do que os do presente estudo aos 65 DAS.

As maiores plantas e maiores biomassas da parte aérea e total do Dipteryx alata Vog. foram verificadas no telado preto (Tabela 5), que provoca redução de $41 \%$ da radiação global externa (Pezzopane et al., 2004). O telado aluminizado promove redução de $54,4 \%$, segundo Rocha (2007), e de 58,8\% segundo Santos et al. (2010).

A radiação fotossinteticamente ativa (RFA) é uma fração da radiação global externa (RGE) e pode ser expressa em função dela. Para telado preto, Pezzopane et al. (2004) encontraram que a RFA é proporcional a 1,97 da RGE e, para telado aluminizado, Leite (2008) relata que a RFA é proporcional a 1,82 da RGE.

Observa-se que tanto a RGE como a RFA são maiores em telado preto. Essa maior disponibilidade de radiação 
no telado preto propiciou melhores condições para as plantas realizarem fotossíntese (Taiz \& Zeiger, 2004) e dessa forma promoveu melhor crescimento e acúmulo de biomassa do Dipteryx alata Vog.

Pezzopane et al. (2004) afirmam que as telas aluminizadas contribuem para a diminuição da transpiração da cultura à noite e, consequentemente, para a redução do calor consumido por evapotranspiração, no entanto essas características não propiciaram mudas de melhor qualidade que as obtidas no telado preto. Segundo Costa (2004), a tela aluminizada reflete parte da energia solar incidente, promove menores temperaturas no verão e maiores no inverno, difunde a luz no interior do ambiente e aumenta a eficiência da fotossíntese, características que não influenciaram na obtenção de mudas de melhor qualidade que as obtidas no telado preto.

No telado preto, os substratos com porcentagens de esterco de $10 \%, 20 \%$ e $30 \%$ propiciaram plantas com maior biomassa seca do sistema radicular e as menores relações entre biomassa aérea e radicular foram observadas nas plantas cultivadas nos substratos com $10 \%$ e $20 \%$ de esterco, variando essa relação de 2,17 a 2,29 (Tabela 6). No telado aluminizado, o substrato com $20 \%$ de esterco propiciou plantas com maior biomassa radicular e as maiores partições da biomassa entre a parte aérea e radicular foram observadas nas plantas

Tabela 5. Efeito do ambiente na altura da planta aos 65 dias após a semeadura; na biomassa seca da parte aérea; na biomassa seca total; e na relação altura da muda e diâmetro do colo do Dipteryx alata Vog., em Cassilândia, MS, novembro de 2012 a janeiro de 2013.

Table 5. Effects of environments on plant height at 65 days after sowing, on aerial part dry biomass, on total dry biomass and on ratio of plant height and stem diameter of Dipteryx alata Vog. Cassilândia-MS, November-2012 to January-2013.

\begin{tabular}{|ccccc} 
& $\begin{array}{c}\text { Altura da planta aos } \\
\mathbf{6 5} \text { dias }\end{array}$ & $\begin{array}{c}\text { Biomassa seca da } \\
\text { parte aérea }\end{array}$ & Biomassa seca total & $\begin{array}{c}\text { Relação altura e } \\
\text { diâmetro do colo }\end{array}$ \\
\hline Tela preta & $18,90 \mathrm{~A}$ & $2,536 \mathrm{~A}$ & $3,316 \mathrm{~A}$ & $4,08 \mathrm{~A}$ \\
\hline Tela aluminizada & $17,43 \mathrm{~B}$ & $2,287 \mathrm{~B}$ & $3,077 \mathrm{~B}$ & $3,82 \mathrm{~B}$ \\
\hline
\end{tabular}

Letras iguais maiúsculas nas colunas, para cada parâmetro, não diferem entre si pelo teste $\mathrm{F}$ a $5 \%$ de probabilidade.

Tabela 6. Efeito do ambiente e da composição de substratos na biomassa seca do sistema radicular, na relação biomassa seca aérea e radicular e no índice de qualidade de Dickson de Dipteryx alata Vog., em Cassilândia, MS, novembro de 2012 a janeiro de 2013.

Table 6. Effects of environments and substrates composition on root dry biomass, on ratio of aerial part dry biomass and root dry mass and on Dickson quality index of Dipteryx alata Vog. Cassilândia-MS, November-2012 to January-2013.

\begin{tabular}{|c|c|c|c|c|c|c|}
\hline & \multicolumn{2}{|c|}{$\begin{array}{c}\text { Biomassa seca do sistema radi- } \\
\text { cular }\end{array}$} & \multicolumn{2}{|c|}{$\begin{array}{c}\text { Relação biomassa seca aérea e } \\
\text { radicular }\end{array}$} & \multicolumn{2}{|c|}{$\begin{array}{c}\text { Indice de qualidade de } \\
\text { Dickson }\end{array}$} \\
\hline & Tela preta & Tela aluminizada & Tela preta & Tela aluminizada & Tela preta & Tela aluminizada \\
\hline S1 & 0,614 Ba & $0,434 \mathrm{Da}$ & $3,45 \mathrm{Ba}$ & $4,19 \mathrm{Aa}$ & $0,411 \mathrm{Ba}$ & $0,293 \mathrm{Cb}$ \\
\hline $\mathrm{S} 2$ & $0,588 \mathrm{Ba}$ & $0,651 \mathrm{Ca}$ & $3,83 \mathrm{Ba}$ & 3,35 Ba & $0,376 \mathrm{Ba}$ & 0,397 Ba \\
\hline S3 & $0,802 \mathrm{Ba}$ & $0,508 \mathrm{Db}$ & $3,28 \mathrm{Bb}$ & $4,14 \mathrm{Aa}$ & $0,475 \mathrm{Aa}$ & $0,333 \mathrm{Cb}$ \\
\hline S4 & $0,738 \mathrm{Ba}$ & $0,667 \mathrm{Ca}$ & $3,50 \mathrm{Ba}$ & $3,55 \mathrm{Ba}$ & $0,410 \mathrm{Ba}$ & $0,403 \mathrm{Ba}$ \\
\hline S5 & $0,630 \mathrm{Ba}$ & $0,689 \mathrm{Ca}$ & $4,31 \mathrm{Aa}$ & $3,63 \mathrm{Ba}$ & $0,390 \mathrm{Ba}$ & $0,420 \mathrm{Ba}$ \\
\hline S6 & $0,642 \mathrm{Bb}$ & $0,890 \mathrm{Ba}$ & $4,45 \mathrm{Aa}$ & $3,13 \mathrm{Bb}$ & $0,401 \mathrm{Bb}$ & $0,517 \mathrm{Aa}$ \\
\hline S7 & $0,713 \mathrm{Ba}$ & $0,869 \mathrm{Ba}$ & $3,48 \mathrm{Ba}$ & $2,84 \mathrm{Ca}$ & $0,403 \mathrm{Ba}$ & $0,480 \mathrm{Aa}$ \\
\hline S8 & $0,953 \mathrm{Aa}$ & $0,982 \mathrm{Ba}$ & 3,44 Ba & $2,63 \mathrm{Ca}$ & $0,525 \mathrm{Aa}$ & $0,523 \mathrm{Aa}$ \\
\hline S9 & $1,023 \mathrm{Aa}$ & 1,205 Aa & $2,29 \mathrm{Ca}$ & $2,18 \mathrm{Ca}$ & 0,532 Aa & 0,594 Aa \\
\hline S10 & $1,101 \mathrm{Aa}$ & $0,999 \mathrm{Ba}$ & $2,17 \mathrm{Ca}$ & $2,27 \mathrm{Ca}$ & $0,568 \mathrm{Aa}$ & $0,534 \mathrm{Aa}$ \\
\hline
\end{tabular}

Letras iguais, maiúsculas nas colunas e minúsculas nas linhas, para cada parâmetro, não diferem entre si pelo teste de Scott-Knott a $5 \%$ de probabilidade e pelo teste $\mathrm{F}$ para os ambientes de cultivo; $\mathrm{S} 1=100 \%$ de $\mathrm{E}+0 \%$ de V; $\mathrm{S} 2=90 \%$ de $\mathrm{E}+10 \%$ de V; S3 $=80 \%$ de $\mathrm{E}$ $+20 \%$ de V; $S 4=70 \%$ de $\mathrm{E}+30 \%$ de V; S5 = 60\% de $\mathrm{E}+40 \%$ de V; S6 = 50\% de E + 50\% de V; S7 = 40\% de E + 60\% de V; S $8=30 \%$ de $\mathrm{E}+70 \%$ de V; $\mathrm{S} 9=20 \%$ de $\mathrm{E}+80 \%$ de V; $\mathrm{S} 10=10 \%$ de $\mathrm{E}+90 \%$ de $\mathrm{V}$. 
cultivadas nos substratos com 10\%, 20\%, 30\% e 40\% de esterco bovino, com a relação variando de 2,18 a 2,84.

A razão da partição da biomassa entre a parte aérea e radicular, indicativa de qualidade para mudas de espécies florestais, segundo Brissette (1984), se estabelece no valor 2 , ou seja, a biomassa área sendo o dobro da biomassa radicular. Pelo exposto, para ambos ambientes, os substratos S9 e S10 apresentaram plantas com maiores indicativos de qualidade pela partição de biomassas que os demais substratos.

O substrato $\mathrm{S} 9(20 \% \mathrm{E}+80 \% \mathrm{~V})$ promoveu plantas com sistema radicular de $1,023 \mathrm{~g}$ no telado preto e com 1,205 g no telado aluminizado (Tabela 6), similar ao resultado obtido por Costa et al. (2012), que foi de $1,25 \mathrm{~g}$ em substrato contendo $100 \%$ de vermiculita adubada. No presente trabalho, as maiores biomassas foram obtidas em substratos com elevada quantidade de vermiculita e baixa quantidade de esterco, pois o Dipteryx alata Vog., por ser planta de Cerrado e adaptada a solos pobres em nutrição, desenvolveu melhor seu sistema radicular em substratos com menores quantidades de esterco.

O índice de qualidade de Dickson (IQD), relação entre a biomassa total da muda e a soma da relação entre altura/diâmetro e biomassa seca da parte aérea e radicular (Dickson et al., 1960), por envolver vários parâmetros em sua determinação, é considerado indicador de vigor das mudas. No presente trabalho, os substratos com porcentagens menores de esterco promoveram plantas mais vigorosas (Tabela 6), assim como observado para a biomassa seca do sistema radicular. O máximo IQD encontrado foi de 0,594, enquanto Costa et al. (2012) verificaram 0,64 na vermiculita (100\%).

Nos substratos com resultados superiores, a biomassa seca radicular, as relações entre as biomassas e os índices de qualidade de Dickson foram similares nos dois ambientes telados (Tabela 6), assim como observado por Costa et al. (2012).

\section{CONCLUSÕES}

A emergência das plântulas de Dipteryx alata Vog. foi indiferente ao sombreamento com tela preta ou aluminizada, ambas com $50 \%$ de sombreamento.
Os substratos com baixas porcentagens de esterco (10\%, 20\% e 30\%) são os mais propícios para a formação de mudas de Dipteryx alata Vog.

O telado preto propiciou mudas de melhor qualidade que o telado aluminizado.

\section{AGRADECIMENTOS}

À Universidade Estadual de Mato Grosso do Sul (PIBIC/UEMS/FUNDECT). Ao CNPq, Proc. N. 300829/2012-4; à Fundect, Proc. N. 23/200.647/2012.

\section{STATUS DA SUBMISSÃO}

Recebido: 20 dez., 2013

Aceito: 21 abr., 2015

\section{AUTOR PARA CORRESPONDÊNCIA}

\section{Edilson Costa}

Unidade Universitária de Cassilândia, Universidade Estadual de Mato Grosso do Sul UEMS, Rodovia MS 306, km 6,4, CEP 79540-000, Cassilândia, MS, Brasil

e-mail: mestrine@uems.br

\section{APOIO FINANCEIRO}

CNPq, Proc. No 300829/2012-4; FUNDECT, Proc. $\mathrm{N}^{\circ} 23 / 200.647 / 2012$ e PNPD/CAPES.

\section{REFERÊNCIAS}

Ajalla ACA, Volpe E, Vieira MC, Zarate NAH. Produção de mudas de baru (Dipteryx alata Vog.) sob três níveis de sombreamento e quatro classes texturais de solo. Revista Brasileira de Fruticultura 2012; 34(3): 888-896. http:// dx.doi.org/10.1590/S0100-29452012000300031.

Banzatto DA, Kronka SN. Experimentação agrícola. 3. ed. Jaboticabal: Funep; 2006.

Brissette JC. Summary of discussions about seedling quality. In: Southern Nursery Conferences [online]; 1984; Alexandria. New Orleans: USDA. Forest Service, Southern Forest Experiment Station; 1984 [acesso em 2013 dez. 3]. Disponível em: www.rngr.net/publications/ proceedings/1984/summary-of-discussions-about-seedquality/at_download/file Summary of discussions about seedling quality 
Carneiro JGA. Determinação do padrão de qualidade de mudas de Pinus taeda para plantio definitivo [dissertação]. Curitiba: Universidade Federal do Paraná; 1976. 70 p.

Carneiro JGA. Produção e controle de qualidade de mudas florestais. Curitiba: UFPR/FUPEF; 1995. 451 p.

Carneiro JGA. Variações na metodologia de produção de mudas florestais afetam os parâmetros morfofisiológicos que indicam a sua qualidade. Curitiba: FUPEF; 1983. Série Técnica n. 12.40 p.

Carneiro JGA, Barroso DG, Soares LMS. Crescimento de mudas em raiz nua de Pinus taeda, L. produzidas em cinco densidades no viveiro. Scientia Agricola 2007; 64(1): 23 29. http://dx.doi.org/10.1590/S0103-90162007000100004.

Chaves LLB, Carneiro JGA, Barroso DG. Crescimento de mudas de Anadenanthera macrocarpa (Benth) Brenan (angico -vermelho) em substrato fertilizado e inoculado com rizóbio. Revista Árvore 2006; 30(6): 911-919. http:// dx.doi.org/10.1590/S0100-67622006000600006.

Corrêa GC, Rocha MR, Naves RV. Germinação de sementes e emergência de plântulas de baru (Dipteryx alata Vog.) nos Cerrados do Estado de Goiás. Pesquisa Agropecuária Tropical [online]. 2000 [citado em 2013 dez. 3]; 30(2): 17-23. Disponível em: http://www.revistas.ufg.br/index. php/pat/article/view/2580

Costa E, Leal PAM, Mesquita VAG, Sassaqui AR. Efeitos do Organosuper e do ambiente protegido na formação de mudas de mamoeiro. Engenharia Agrícola 2011; 31(1): 4155. http://dx.doi.org/10.1590/S0100-69162011000100005.

Costa E, Oliveira LC, Santo TLE, Leal PAM. Production of baruzeiro seedling in different protected environments and substrates. Engenharia Agrícola 2012; 32(4): 633-641. http://dx.doi.org/10.1590/S0100-69162012000400002.

Costa E, Santos LCR, Vieira LCR. Produção de mudas de mamoeiro utilizando diferentes substratos, ambientes de cultivo e recipientes. Engenharia agrícola 2009; 29(4): 528537. http://dx.doi.org/10.1590/S0100-69162009000400003.

Costa MC, Albuquerque MCF, Albrecht JMF, Coelho MFB. Substratos para produção de mudas de Jenipapo (Genipa americana L.). Pesquisa Agropecuária Tropical [online]. 2005 [citado em 2013 dez. 3]; 35(1): 19-24. Disponível: http://www.revistas.ufg.br/index.php/pat/ article/view/2280/2243

Costa VM. Desenvolvimento de mudas de cafeeiro produzidas em tubetes, sob malhas termo-refletoras e malha negra [Dissertação]. Piracicaba: Escola Superior de Agricultura Luiz de Queiroz, Universidade de São Paulo; 2004.

Dias R, Melo B, Rufino MA, Silveira DL, Morais TP, Santana DG. Fontes e proporção de material orgânico para a produção de mudas de cafeeiro em tubetes. Ciência e Agrotecnologia 2009; 33(3): 758-764. http://dx.doi. org/10.1590/S1413-70542009000300014.

Dickson A, Leaf AL, Hosner JF. Quality appraisal of white spruce and white pine seedling stock in nurseries. Forestry
Chronicle 1960; 36(1): 10-13. http://dx.doi.org/10.5558/ tfc36010-1.

Fachinello JC, Hoffmann A, Nachtigal JC. Propagação de plantas frutíferas de clima temperado. 2. ed. Pelotas: UFPel; 1995.

Ferreira DF. SISVAR - Sistema de análise de variância. Versão 5.3. Lavras: UFLA; 2010.

Ferreira RA, Botelho AS, Davide AC, Malavasi MM. Caracterização morfológica de fruto, semente, plântula e muda de Dipteryx alata Vogel - baru (Leguminosae Papilionoideae). Cerne [online]. 1998 [citado em 2013 dez. 13]; 4(1): 73-87. Disponível em: http://www.dcf.ufla. br/cerne/artigos/13-02-20099702v4_n1_artigo\%2005.pdf

Fonseca CEL, Figueiredo AS, Silva JA. Influência da profundidade de semeadura e da luminosidade na germinação de sementes de baru (Dipteryx alata Vog). Pesquisa Agropecuaria Brasileira 1994; 29(4): 653-659.

Labouriau LG. A germinação de sementes. Washington: OEA; 1983.

Leite COM. Uso de malhas termo-refletoras e malha negra no cultivo hidropônico da alface [dissertação]. Mossoró: Universidade Federal Rural do Semi-Árido - UFERSA; 2008.

Maguire JD. Speed of germination aid in selection and evaluation of seedling emergence and vigor. Crop Science 1962; 2(2): 176-177. http://dx.doi.org/10.2135/cropsci19 62.0011183X000200020033x

Menezes FOG Jr, Fernandes HS. Efeitos de substratos formulados com esterco de curral e substratos comerciais na produção de mudas de alface. Revista Científica Rural [online]. 1999 [citado em 2013 dez. 13]; 4(2): 15-23. Disponível em: http://www.bdpa.cnptia.embrapa.br/ busca $\mathrm{b}=\mathrm{ad} \& \mathrm{~d}=766898 \&$ biblioteca $=$ vazio\&busca $=\mathrm{a}$ utoria:\%22MENEZES\%20J\%C3\%9ANIOR,\%20F.\%20 O.\%20G.\%22\&qFacets=autoria:\%22MENEZES\%20 J\%C3\%9ANIOR,\%20F.\%20O.\%20G.\%22\&sort=\&pagin acao $=\mathrm{t} \&$ paginaAtual $=1$

Mota LHS, Scalon SPQ, Heinz R. Sombreamento na emergência de plântulas e no crescimento inicial de Dipteryx alata Vog. Ciência Florestal 2012; 22(3): 423-431. http://dx.doi.org/10.5902/198050986611.

Peixoto JR. Efeito da matéria orgânica, do superfosfato simples e do cloreto de potássio na formação de mudas de maracujazeiro azedo (Passiflora edulis $f$. flavicarpa DENEGER) [dissertação]. Lavras: Escola Superior de Agricultura Lavras; 1986.

Pezzopane JEM, Oliveira PC, Reis EF, Lima JSS. Alterações microclimáticas causadas pelo uso da tela plástica. Engenharia Agrícola 2004; 24(1): 9-15.

Reis LS, Azevedo CVA, Albuquerque AW, Silva JF Jr. Índice de área foliar e produtividade do tomate sob condições de ambiente protegido. Revista Brasileira de Engenharia Agrícola e Ambiental 2013; 17(4): 386-391. http://dx.doi. org/10.1590/S1415-43662013000400005. 
Rocha RC. Uso de diferentes telas de sombreamento no cultivo protegido do tomateiro [dissertação]. Botucatu: Universidade Estadual Paulista Júlio De Mesquita Filho; 2007.

Sano SM, Ribeiro JF, De Brito MA. Baru: biologia e uso [online]. Planaltina: Embrapa Cerrados; 2004 [citado em 2013 dez. 13]. Documentos n. 116. Disponível em: www. cpac.embrapa.br/download/336/t

Santos LL, Seabra S Jr, Nunes MCM. Luminosidade, temperatura do ar e do solo em ambientes de cultivo protegido. Revista de Ciências Agro-Ambientais 2010; 8(1): 83-93.
Silva JA, Silva DB, Junqueira NT, Andrade LRM. Frutas nativas dos cerrados. Brasília-DF: EMBRAPA/CPAC; 1994.

Taiz L, Zeiger E. Fisiologia vegetal. 3. ed. Porto Alegre: Artmed; 2004.

Vera R, Souza ERB. Baru. Revista Brasileira de Fruticultura 2009; 31(1): 1-1. http://dx.doi.org/10.1590/S010029452009000100001.

Zanella F, Soncela R, Lima ALS. Formação de mudas de maracujazeiro "amarelo" sob níveis de sombreamento em Ji-Paraná/RO. Ciência e Agrotecnologia 2006; 30(5): 880884. http://dx.doi.org/10.1590/S1413-70542006000500009. 